\title{
Synthesis of Carbon Nanomaterials from Rice Husk via Microwave Oven
}

\author{
Muhammad Asnawi (D), Saman Azhari $\mathbb{D}$, Mohd Nizar Hamidon, \\ Ismayadi Ismail, and Intan Helina \\ Institute of Advanced Technology (ITMA), Universiti Putra Malaysia (UPM), 43400 Serdang, Selangor, Malaysia
}

Correspondence should be addressed to Muhammad Asnawi; muhdasnawi92@gmail.com

Received 21 November 2017; Accepted 4 January 2018; Published 27 February 2018

Academic Editor: Stefano Bellucci

Copyright ( 2018 Muhammad Asnawi et al. This is an open access article distributed under the Creative Commons Attribution License, which permits unrestricted use, distribution, and reproduction in any medium, provided the original work is properly cited.

\begin{abstract}
Microwave oven was utilized to fabricate carbon nanostructure, specifically CNTs, from waste RH powders. It has been shown that the use of carbon source, catalyst, and commercial microwave oven to induce plasma is necessary to carry on this synthesis. The plasma enhances and speeds up the catalytic decomposition of RH in presence of ferrocene. FESEM, TGA, and Raman spectroscopy were utilized to confirm the presence and quality of produced carbon nanomaterials. In addition, these results suggest the conversion of ferrocene to iron(II, III) oxide with notable conversion rate.
\end{abstract}

\section{Introduction}

Nanocarbons including fullerene, graphene, nanodiamonds, nanotubes, and activated carbon have unique physical and chemical properties leading the extensive research interest and exhibit promising applications [1-4]. Among them, graphene and carbon nanotubes are the most interactive stars in the field of nanotechnology. These carbon structures have proven strong potentials in revolutionizing wide range of applications globally. Basically, they can be classified as zero-dimensional (0D) fullerenes, one-dimensional (1D) carbon nanotubes, two-dimensional (2D) graphene, and three-dimensional (3D) graphite which consist of carbon as the building block $[5,6]$. CNTs are made of hexagonal network of $\mathrm{sp}^{2}$ hybridization of carbon atoms that is similar to graphene [1]. CNTs are the strongest materials due to carboncarbon $\sigma$ bonds and can be mainly categorized into singlewall carbon nanotubes (SWCNTs) and multiwall carbon nanotubes (MWCNTs) [7]. They consist of honeycombed lattice carbon sheets with interlayer spacing of $0.32-0.35 \mathrm{~nm}$ and 2 to 50 sheets tubules range of wall thickness [8].

Novel structure of CNTs has led to their remarkable properties including high chemical stability, excellent electrical conductivity, and high mechanical properties [9].
Compared to CNTs, graphene possesses special features, for instance, high reactivity of graphene edge [10] and high light transmittance [11]. Exceptional electrical, mechanical, thermal, and electrochemical properties are exhibited by CNTs; it is widely used in semiconductor, sensor, superconductive electrode, drug delivery, and other forms of electronics [12]. So far, various techniques for synthesis of CNTs had been reported: laser ablation [13], chemical vapor deposition [14], arc-discharge [15], flame synthesis [16], and high-pressure carbon monoxide (HiPCO) [17].

Recently, the synthesis of CNTs using waste product has received attention from researchers. In this study, a residue from paddy called rice husk (RH) is used to synthesize CNTs using microwave oven (MO) technique [18]. $\mathrm{RH}$ is rich in cellulose and lignin which qualifies it as a good and economic source of carbon precursor [19].

Raman spectroscopy and field emission scanning electron microscope (FESEM) as well as thermal gravimetric analysis (TGA) have confirmed the presence of carbon nanomaterials consisting of CNTs and other structures. On the basis of our experimental result combined with previous works a possible growth mechanism in conversion of RHs into carbon nanomaterials has been proposed [20]. 


\section{Experimental Details}

2.1. Synthesis of Carbon Nanomaterials. Rice husks were washed and cleaned by distilled water from unwanted materials using sonication; $\mathrm{RH}$ was then dried for 24 hours at $65^{\circ} \mathrm{C}$. The dried $\mathrm{RH}$ was mechanically ground into powder by commercial blender machine and sieved using laboratory test sieve of $\sim 20 \mu \mathrm{m}$. Ferrocene, $\mathrm{Fe}\left(\mathrm{C}_{5} \mathrm{H}_{5}\right)_{2}$, as catalyst was dissolved into ethanol and sonicated for 20 minutes at room temperature. $120 \mathrm{mg}$ of dried $\mathrm{RH}$ powder and $80 \mathrm{mg}$ of $\mathrm{Fe}\left(\mathrm{C}_{5} \mathrm{H}_{5}\right)_{2}$ solution were mixed together and placed on $2.5 \mathrm{~cm} \times 2.5 \mathrm{~cm}$ aluminum sheet as substrate. Aluminum sheet was then covered with a handmade aluminum casing, $\varnothing 40 \mathrm{~mm}$ (diameter) $\times 10 \mathrm{~mm}$ (height). The sample was then placed at the center of the quartz tube inside the microwave oven (Samsung M539 MAN200405W), 600 W power and $2.45 \mathrm{GHz}$ frequency (household microwave frequency). Prior to microwave plasma irradiation, the quartz tube was evacuated into base pressure of $1.3 \times 10^{\circ} \mathrm{mbar}$. Deposition time was employed for 38 minutes. Even though plasma forms shortly after switching on the microwave, it will not react rapidly to form CNTs. This is because, within 5-30 minutes, production of amorphous carbon is more likely to occur. It has also been reported that under plasma radiation amorphous carbon forms if the process exceeds 40 minutes [20]. The tube pressure was controlled by a rotary pump and a leak valve. No additional heater was installed in the system for substrate heating; however the substrate temperature could increase with increasing the growth time. During the growth process, quartz tube pressure initially increased to $3 \times 10^{\circ} \mathrm{mbar}$ and finally decreased to $1 \times 10^{\circ} \mathrm{mbar}$. Thermocouple was placed in direct contact with the substrate holder to measure the substrate temperature. After irradiation, the sample was cooled down naturally to room temperature. After the plasma processing, the top of aluminum foil case was covered by soot-like appearance as shown in Figure 1(b).

2.2. Material Characterization. The microstructure morphological analysis was performed using a field emission scanning electron microscope (FESEM) operated at $10 \mathrm{kV}$. The crystalline structure was investigated via Raman spectroscopy using $532 \mathrm{~nm}$ laser. To determine the amount of catalyst impurities thermal gravimetric analysis (TGA) under air was utilized.

\section{Result and Discussion}

Figures 1(a) and 1(b) show the schematic diagram of $\mathrm{MO}$ technique for derivation of carbon nanomaterials from $\mathrm{RH}$. The synthesis process as explained in experimental section shows that synthesis pressure plays a crucial role in synthesizing carbon nanomaterials from $\mathrm{RH}$. The $\mathrm{RH}$ powders were irradiated for maximum time of 38 minutes. The maximal temperature and pressure were $750^{\circ} \mathrm{C}$ and $3 \times 10^{\circ} \mathrm{mbar}$, respectively. Figures 2(a) and 2(b) show the growth of CNTs which was investigated using FESEM. CNTs growth has received much attention but yet the growth mechanism remains unclear. From these results it could be hypothesized that, due to strong van der Waals interaction between $\mathrm{RH}$ and catalyst, catalyst coalesces at nucleation sites, stimulating root growth. Figure 2(b) shows a weak interaction between catalyst-RH and substrate (metal has an acute contact angle with the substrate); it seems like that hydrocarbon decomposes from the top surface of RH. It could be assumed that the carbon diffuses down through the $\mathrm{RH}$, and CNTs precipitate out across the metal bottom pushing the $\mathrm{RH}$ particle off the substrate. As long as the $\mathrm{RH}$ top is open for fresh hydrocarbon decomposition, the concentration gradient exists in the metal allowing carbon diffusion and CNTs continue to grow longer. Once the RH is fully covered with excess carbon, its catalytic activity ends and the CNTs growth stopped. This process is called tip growth mechanism.

Figure 2(c) shows the surface morphology of carbon nanocluster and CNTs. The images from FESEM show the formation of CNTs structures. Surface morphology indicates twisted and randomly oriented web-like network, several micrometers long, showing that the reduced powders retain the shape of the reduction vessel. Some of the particles may be onion-like carbon nanostructures. Depending on the nature and amount of the catalyst, some differences are revealed in FESEM images.

Figure 3 shows the corresponding Raman spectrum of the $\mathrm{RH}$ derived carbon nanomaterials with the two prominent $\mathrm{D}$ and $G$ bands. The D peak observed at $1335 \mathrm{~cm}^{-1}$ with FWHM of 105.35 and area of 64.75 , obtained from Gaussian curve fitting, is disordered induced band that is often observed in defective graphitic structures and disordered $\mathrm{sp}^{3}$ hexagonal carbon atom. The $\mathrm{G}$ peak observed at $1601 \mathrm{~cm}^{-1}$ with FWHM of 45.88 and area of 28.92, obtained from Gaussian curve fitting, is associated with the doubly degenerated phonon mode of the Brillouin zone center and indicates the level of order in $\mathrm{sp}^{2}$ hexagonal carbon atom; it is associated with the first-order Raman scattering. The ratio of $\mathrm{D}$ band to G band $\left(I_{\mathrm{D}} / I_{\mathrm{G}}\right)$ is utilized to estimate defects present on carbon nanomaterials. The ratio of $\left(I_{\mathrm{D}} / I_{\mathrm{G}}\right)$ for the synthesized nanomaterials was calculated to be 1.013 . The $\mathrm{D}$ and $\mathrm{G}$ band intensities $\left(I_{\mathrm{D}} / I_{\mathrm{G}}\right)$ indicate lower quality $\mathrm{sp}^{2}$ carbon structures when $\left(I_{\mathrm{D}} / I_{\mathrm{G}}\right)$ ratio is high. Lower quality may arise due to amorphous carbon and structural defects in carbon nanomaterials. Although radial breathing modes (RBM) are the peaks found at the lower wavenumber between $120 \mathrm{~cm}^{-1}$ and $350 \mathrm{~cm}^{-1}$ which depend directly on the nanotubes diameter indicating the presence of SWCNTs the presence of catalyst particles should not be neglected. On one hand these peaks do not appear in MWCNTs which suggest the presence of SWCNTs; on the other hand these peaks positions are similar to the peaks observed and reported previously as hematite and magnetite $[21,22]$. The presence of these peaks suggests the reaction of ferrocene under microwave condition to form various arrangement of iron oxide. The small peak observed at $1488 \mathrm{~cm}^{-1}$ can be attributed to semicircle stretching of carbon atoms in single aromatic ring [23]. Based on this result we may hypothesize that during the synthesis and plasma ionization ferrocene dissociates and elemental iron forms, which then reacts with oxygen dissociated oxygen atoms from RH. This explains the presence of iron(II, III) oxide peaks in the Raman spectrum. It has already been shown 


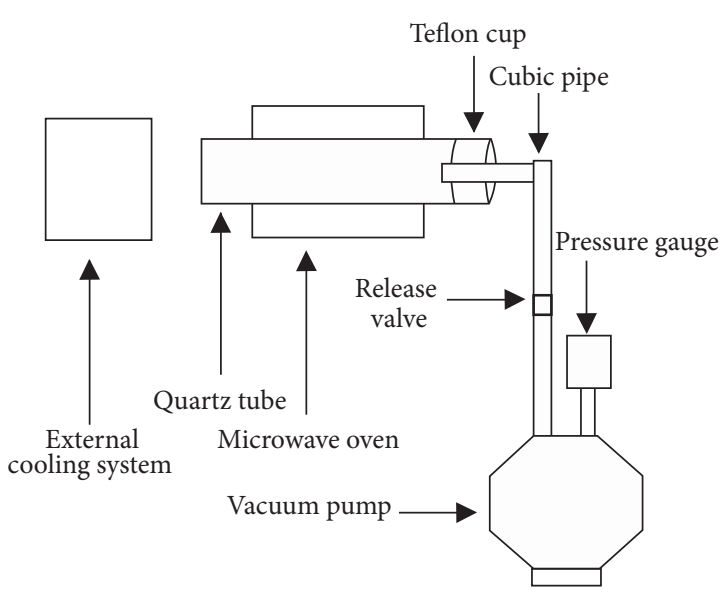

(a)

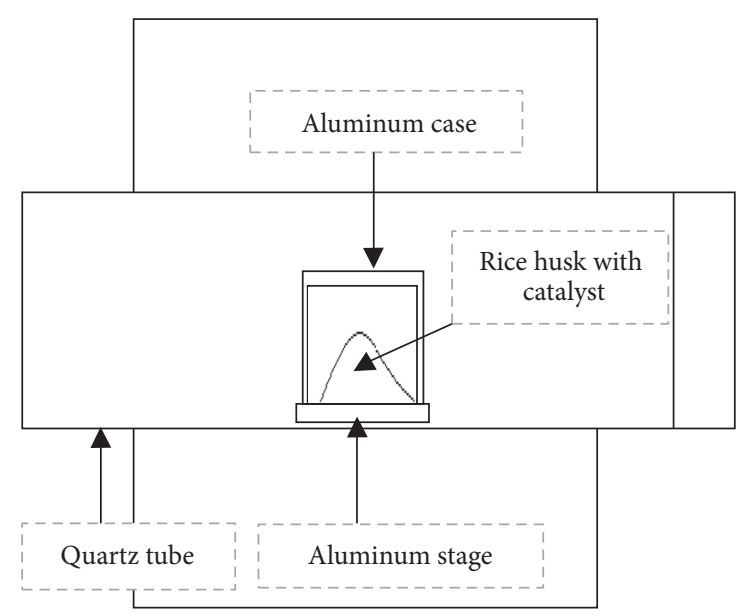

(b)

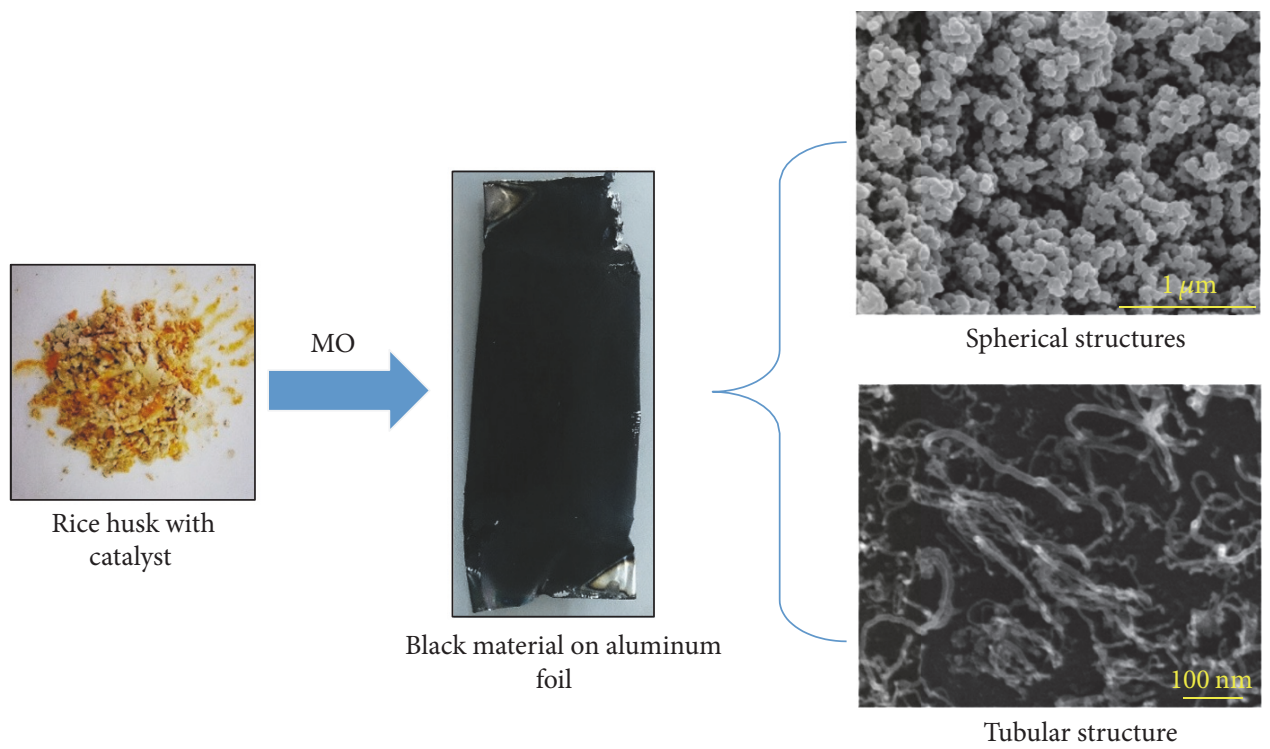

(c)

Figure 1: ((a) and (b)) Schematic diagram of MO technique for carbon nanostructure growth from RHs. (c) The conversion process of RHs soot-like material on the top of aluminum case surface including spherical and tubular structures.

by other groups that the presence of oxygen during CNTs synthesis is crucial [24]. This result indicates that during this process the CNTs growth could be a continuous process if $\mathrm{RH}$ surface remains exposed.

The TGA result shown in Figure 4 exhibits $10 \mathrm{wt} \%$ weight reduction at $343^{\circ} \mathrm{C}$ which may be due to the presence of amorphous carbons and structural defects; the sample then begins to decompose rapidly from $90 \mathrm{wt} \%$ to $4.6 \mathrm{wt} \%$ beginning from $343^{\circ} \mathrm{C}$ to $490^{\circ} \mathrm{C}$, respectively; this suggests the presence of carbon nanomaterials. The DTGA result displays a major peak observed at $421.5^{\circ} \mathrm{C}$ at $50 \mathrm{wt} \%$ which does not seem high enough for CNTs in comparison with results obtained by other research groups; however, this result is justifiable since it has been shown that the presence of iron oxide in CNTs sample may result in lower decomposition temperature [25]. Based on this result we may presume the presence of carbon nanomaterial as a main outcome of the experiment [26].
The residual of the sample at $750^{\circ} \mathrm{C}$ was about $3.7 \mathrm{wt} \%$; this indicates a good conversion rate of ferrocene to carbon nanomaterials.

\section{Conclusion}

We have demonstrated MO process to fabricate carbon nanostructure, specifically CNTs, from waste RH powders. It is necessary to use carbon source, catalyst, and commercial microwave oven to induce plasma. The plasma enhances and speeds up the catalytic decomposition of $\mathrm{RH}$ in presence of ferrocene. In addition, the results suggest the conversion of ferrocene to iron(II, III) oxide with notable conversion rate. CNTs offer great promises for applications such as electrochemical electrodes, due to their special features including high surface area and specific capacitance. This experiment shows that waste biomass can potentially be used as feedstock 


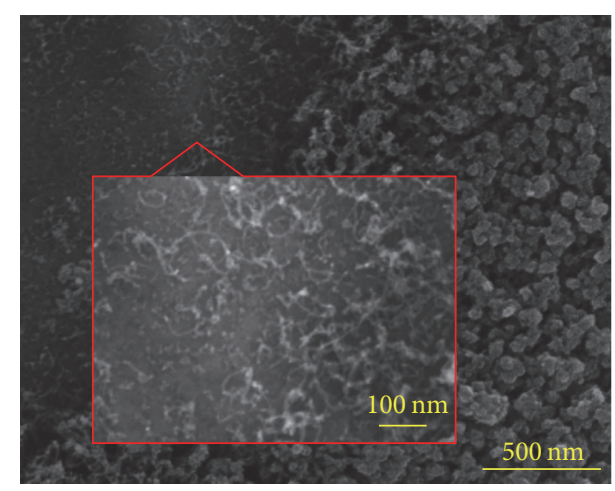

(a)

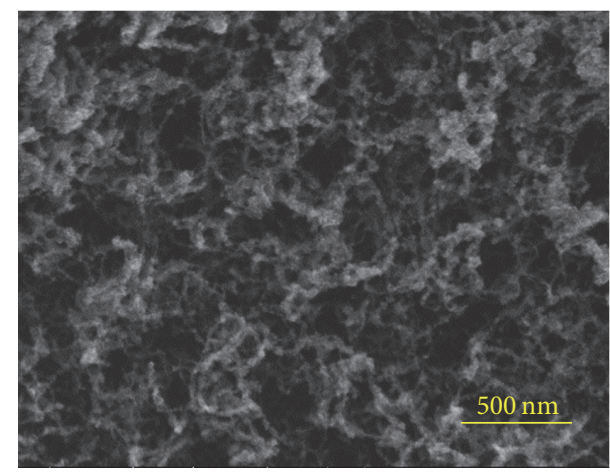

(c)

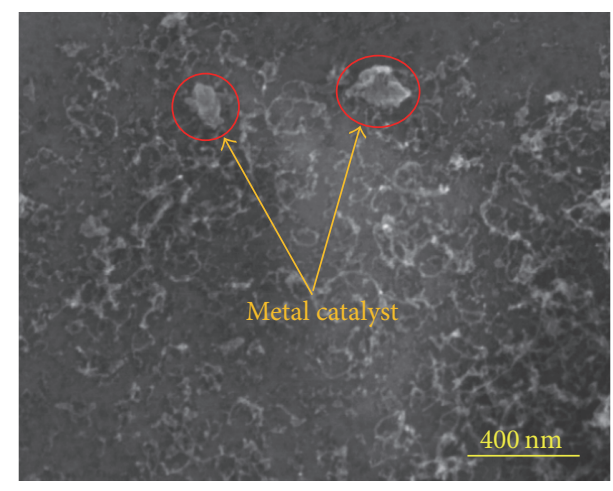

(b)

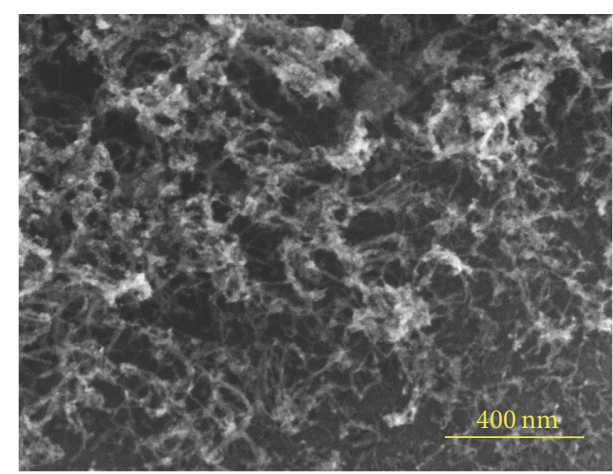

(d)

Figure 2: ((a), (b), (c), and (d)) FESEM images of the RH derived CNTs by MO technique for 38 min.

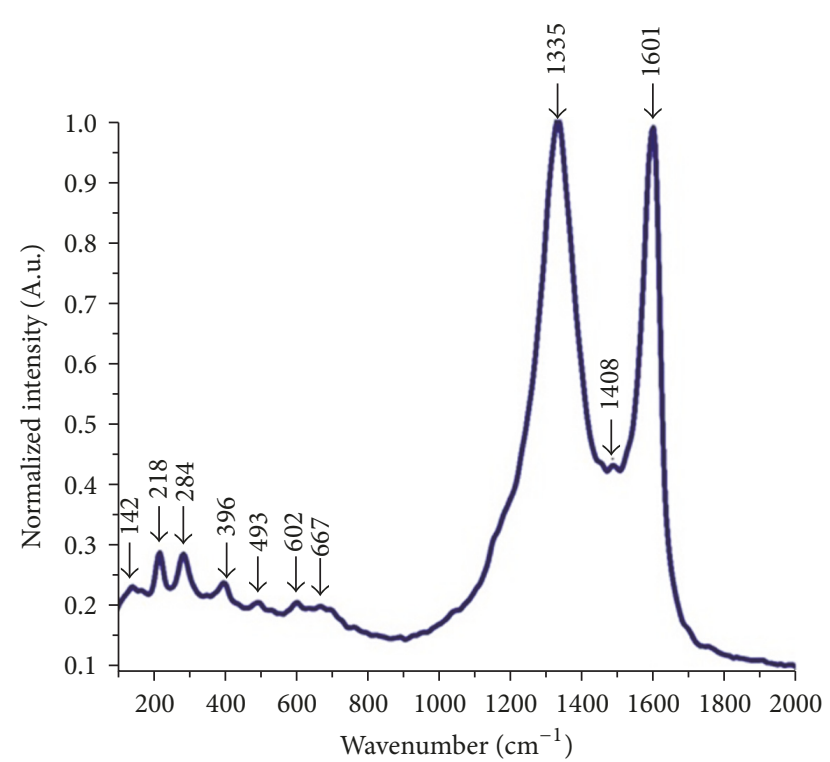

FIGURE 3: Raman spectrum of the prepared sample.

to synthesize carbon nanostructure through MO technique. This would not only valorize waste biomass to achieve highvalue carbon nanostructures, but also solve the environmental issues caused by the huge quantity of waste biomass.

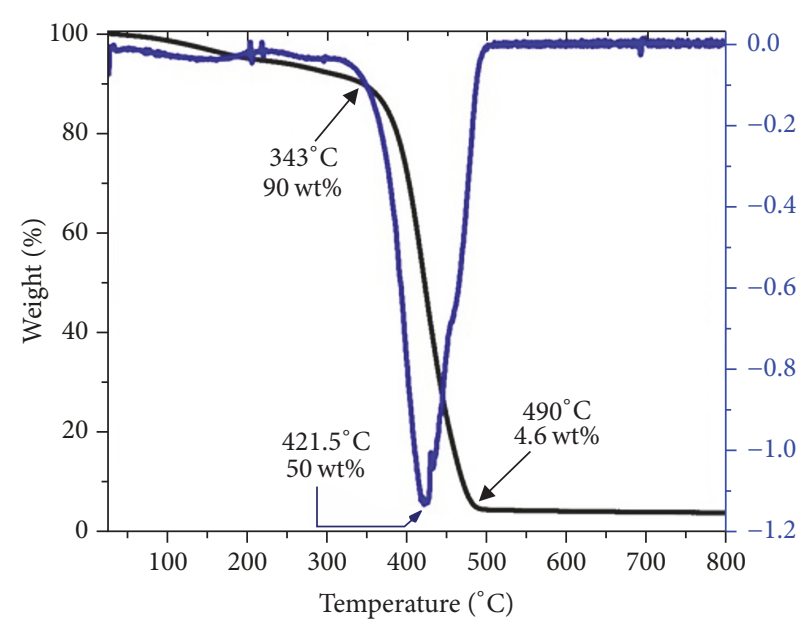

FIGURE 4: TGA and DTGA result obtained from synthesized sample.

\section{Conflicts of Interest}

The authors have no conflicts of interest to declare.

\section{Acknowledgments}

The authors thank Dr. Ismayadi Ismail for many helpful discussions about Raman scattering in graphite and also for 
help with Raman measurement used in Figure 3. In addition, they thank Intan Helina for useful suggestion of FESEM. The work was supported by the Nanomite, Department of Higher Education, Ministry of Higher Education.

\section{References}

[1] P. Greil, "Perspectives of nano-carbon based engineering materials," Advanced Engineering Materials, vol. 17, no. 2, pp. 124-137, 2015.

[2] H. Zhang, X. Zhang, X. Sun, and Y. Ma, "Shape-controlled synthesis of nanocarbons through direct conversion of carbon dioxide," Scientific Reports, vol. 3, no. 1, article 3534, 2013.

[3] V. N. Mochalin, O. Shenderova, D. Ho, and Y. Gogotsi, "The properties and applications of nanodiamonds," Nature Nanotechnology, vol. 7, no. 1, pp. 11-23, 2012.

[4] D.-W. Wang, F. Li, M. Liu, G.-Q. Lu, and H.-M. Cheng, "3D aperiodic hierarchical porous graphitic carbon material for highrate electrochemical capacitive energy storage," Angewandte Chemie International Edition, vol. 47, no. 2, pp. 373-376, 2008.

[5] C. C. Villarreal, T. Pham, P. Ramnani, and A. Mulchandani, "Carbon allotropes as sensors for environmental monitoring," Current Opinion in Electrochemistry, vol. 3, no. 1, pp. 106-113, 2017.

[6] J.-W. Jiang, J. Leng, J. Li et al., “Twin graphene: A novel twodimensional semiconducting carbon allotrope," Carbon, vol. 118, pp. 370-375, 2017.

[7] R. H. Baughman, A. A. Zakhidov, and W. A. de Heer, "Carbon nanotubes - the route toward applications," Science, vol. 297, no. 5582, pp. 787-792, 2002.

[8] J. W. Zhang, Z. Luo, Y. L. Li, J. D. Zhu, and J. Hao, "A welding method for carbon nanotubes," Advanced Materials Research, vol. 160-162, pp. 737-742, 2011.

[9] E. H. Hong, K.-H. Lee, S. H. Oh, and C.-G. Park, "Synthesis of carbon nanotubes using microwave radiation," Advanced Functional Materials, vol. 13, no. 12, pp. 961-966, 2003.

[10] K. E. Whitener and P. E. Sheehan, "Graphene synthesis," Diamond and Related Materials, vol. 46, pp. 25-34, 2014.

[11] R. R. Nair, P. Blake, A. N. Grigorenko et al., "Fine structure constant defines visual transparency of graphene," Science, vol. 320, no. 5881, p. 1308, 2008.

[12] M. F. L. De Volder, S. H. Tawfick, R. H. Baughman, and A. J. Hart, "Carbon nanotubes: present and future commercial applications," Science, vol. 339, no. 6119, pp. 535-539, 2013.

[13] D. Amans, M. Diouf, J. Lam, G. Ledoux, and C. Dujardin, "Origin of the nano-carbon allotropes in pulsed laser ablation in liquids synthesis," Journal of Colloid and Interface Science, vol. 489, pp. 114-125, 2017.

[14] B. K. Pradhan, A. R. Harutyunyan, U. J. Kim, G. Chen, and P. C. Eklund, "CVD synthesis of single wall carbon nanotubes," CVD Synthesis of Single Wall Carbon Nanotubes, vol. 47, no. 2, pp. 431-433, 2002.

[15] N. Arora and N. N. Sharma, "Arc discharge synthesis of carbon nanotubes: comprehensive review," Diamond \& Related Materials, vol. 50, pp. 135-150, 2014.

[16] T. X. Li, K. Kuwana, K. Saito, H. Zhang, and Z. Chen, “Temperature and carbon source effects on methane-air flame synthesis of CNTs," Proceedings of the Combustion Institute, vol. 32, pp. 1855-1861, 2009.

[17] E. Remy, S. Cahen, B. Malaman et al., "Quantitative investigation of mineral impurities of HiPco SWCNT samples: Chemical mechanisms for purification and annealing treatments," Carbon, vol. 93, pp. 933-944, 2015.

[18] N. Kure, M. N. Hamidon, S. Azhari et al., "Simple microwaveassisted synthesis of carbon nanotubes using polyethylene as carbon precursor," Journal of Nanomaterials, vol. 2017, Article ID 2474267, 4 pages, 2017.

[19] H. Ummah, D. A. Suriamihardja, M. Selintung, and A. W. Wahab, "Analysis of chemical composition of rice husk used as absorber plates sea water into clean water," ARPN Journal of Engineering and Applied Sciences, vol. 10, no. 14, pp. 6046-6050, 2015.

[20] Z. Wang, H. Ogata, S. Morimoto et al., "Nanocarbons from rice husk by microwave plasma irradiation: From graphene and carbon nanotubes to graphenated carbon nanotube hybrids," Carbon, vol. 94, pp. 479-484, 2015.

[21] I. Chourpa, L. Douziech-Eyrolles, L. Ngaboni-Okassa et al., "Molecular composition of iron oxide nanoparticles, precursors for magnetic drug targeting, as characterized by confocal Raman microspectroscopy," Analyst, vol. 130, no. 10, pp. 13951403, 2005.

[22] O. N. Shebanova and P. Lazor, "Raman spectroscopic study of magnetite $\left(\mathrm{FeFe}_{2} \mathrm{O}_{4}\right)$ : a new assignment for the vibrational spectrum," Journal of Solid State Chemistry, vol. 174, no. 2, pp. 424-430, 2003.

[23] J. Schwan, S. Ulrich, V. Batori, H. Ehrhardt, and S. R. P. Silva, "Raman spectroscopy on amorphous carbon films," Journal of Applied Physics, vol. 80, no. 1, pp. 440-447, 1996.

[24] M. Kumar and Y. Ando, "Carbon nanotube synthesis and growth mechanism," Nanotechnology Perceptions, vol. 6, no. 1, pp. 7-28, 2010.

[25] Ihsanullah, A. M. Al Amer, T. Laoui et al., "Fabrication and antifouling behaviour of a carbon nanotube membrane," Materials \& Design, vol. 89, pp. 549-558, 2016.

[26] L. S. K. Pang, J. D. Saxby, and S. P. Chatfield, “Thermogravimetric analysis of carbon nanotubes and nanoparticles," The Journal of Physical Chemistry C, vol. 97, no. 27, pp. 6941-6942, 1993. 


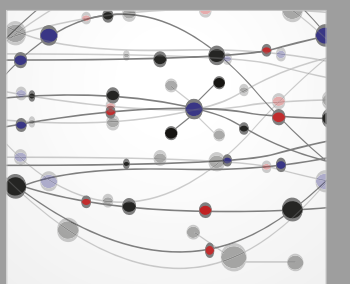

The Scientific World Journal
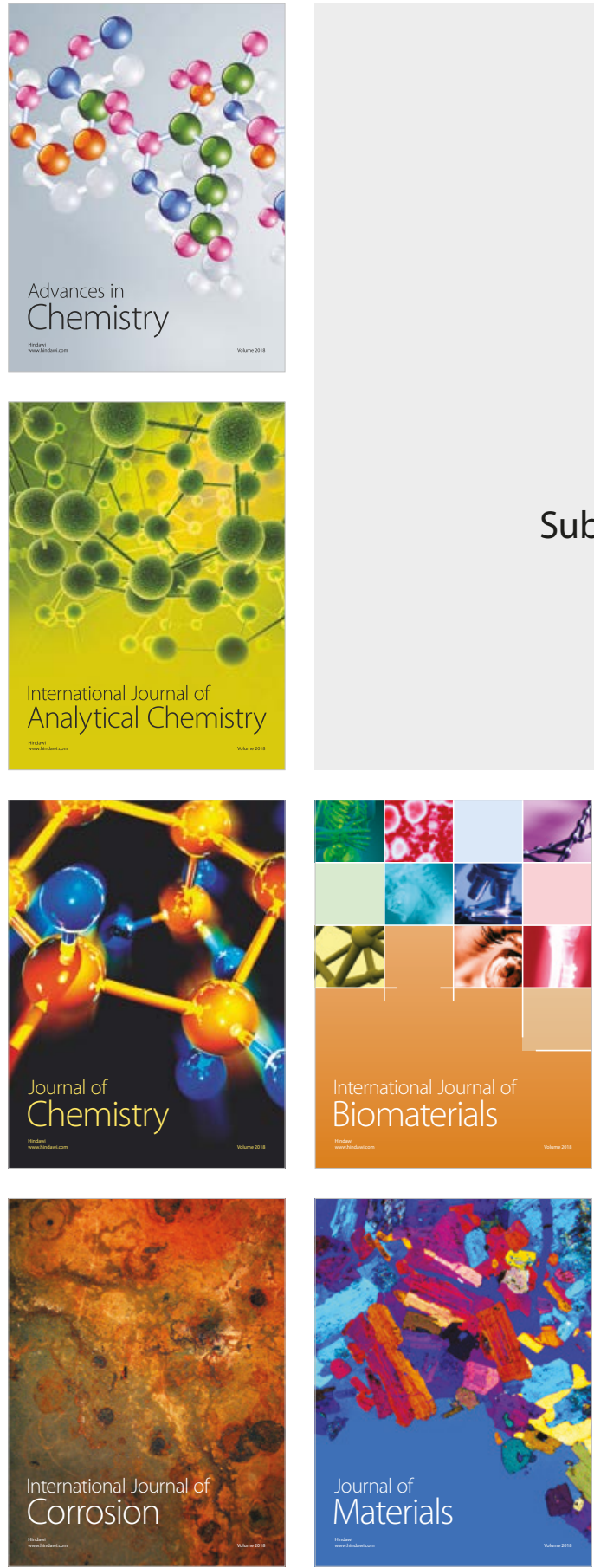

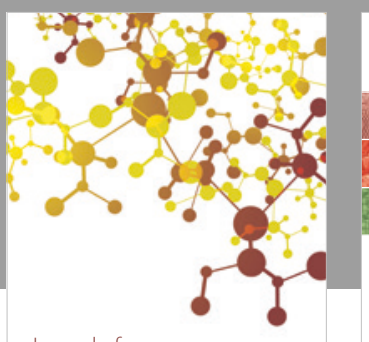

Journal of

Applied Chemistry
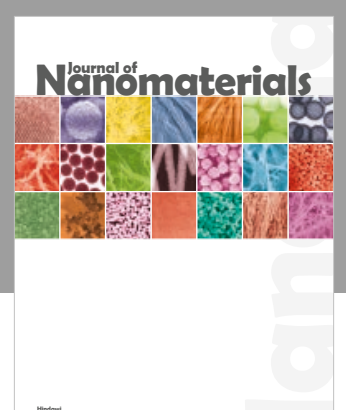

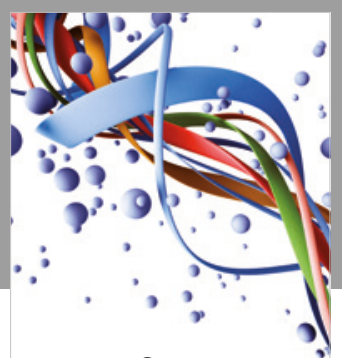

Scientifica

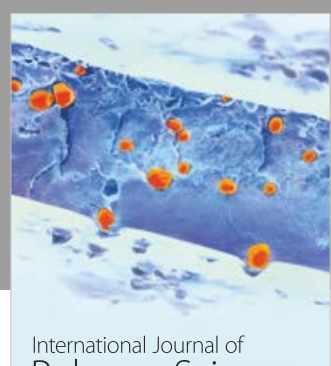

Polymer Science

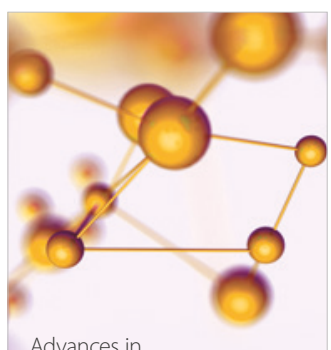

Physical Chemistry
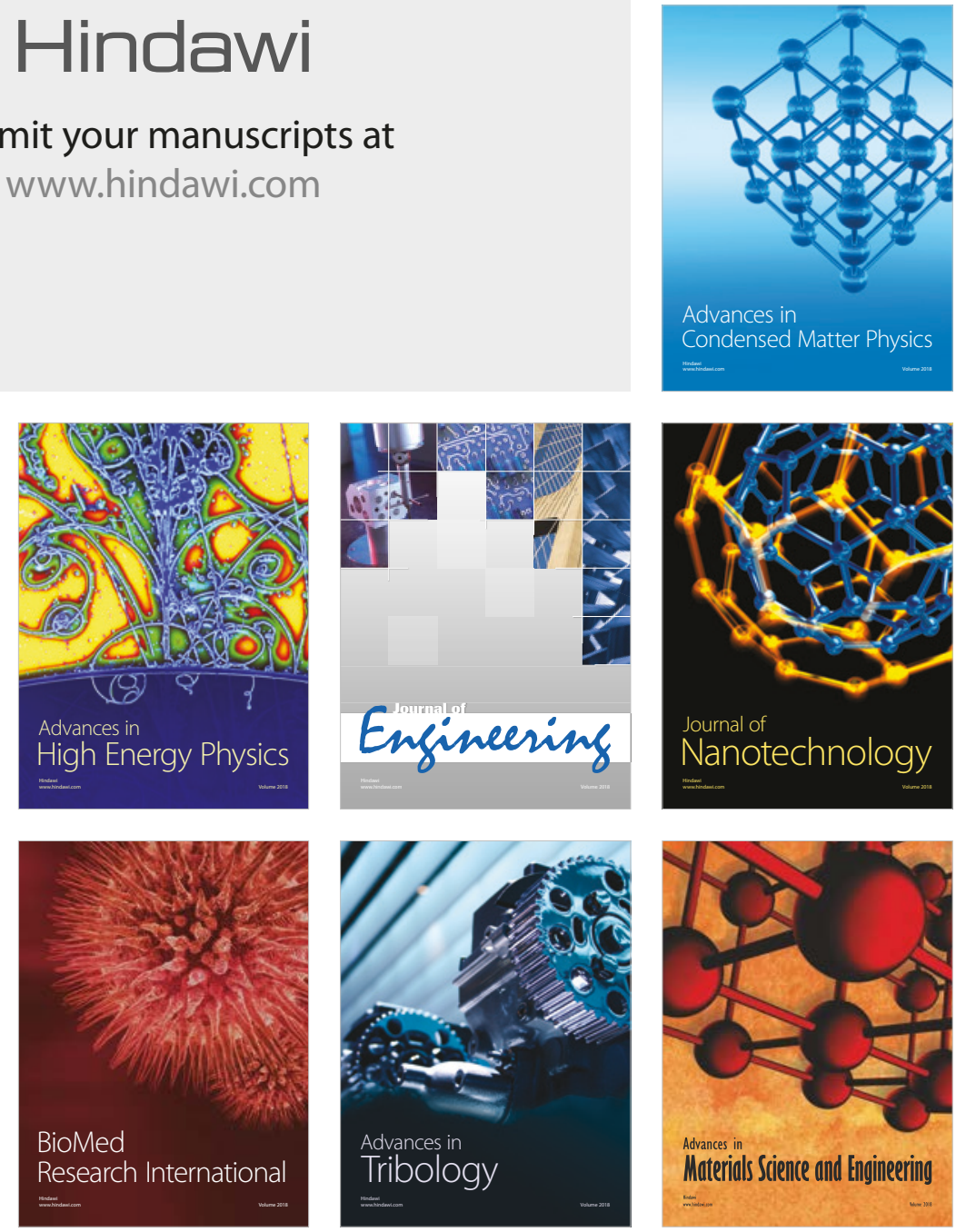